\title{
Monterey Bay Sampling
}

\author{
Richard M. Hodur \\ Naval Research Laboratory \\ Monterey, CA 93943-5502 \\ phone: (831) 656-4788 fax: (831) 656-4769 e-mail: hodur@nrlmry.navy.mil \\ Document \#: N0001403WX20009 \\ http://www.nrlmry.navy.mil/projects/coamps
}

\section{LONG-TERM GOALS}

The goals of this project are to apply high-resolution atmosphere mesoscale modeling to ocean prediction, and assist in the design, plan, and execution of adaptive sampling strategies for the Adaptive Ocean Sampling Network II (AOSN-II) project, Monterey Bay Predictive Skill Experiment.

\section{OBJECTIVES}

The overall objective of AOSN-II is "to quantify the gain in predictive skill for principal circulation trajectories, transport at critical points and near-shore bioluminescence potential in Monterey Bay as a function of model-guided, remote adaptive sampling using a network of autonomous underwater vehicles". A multi-institutional collaborative research program has been established to achieve this objective. Within the scope of this project, our objectives are:

1. Generate real-time, high-resolution surface forcing fields for AOSN-II.

2. Assist in the design, plan, and execution of adaptive sampling strategies for AOSN-II.

\section{APPROACH}

Within our first objective, our approach is to utilize the Coupled Ocean/Atmosphere Mesoscale Prediction System (COAMPS ${ }^{\mathrm{Tm}}{ }^{1}$ ) to construct real-time, high-resolution atmospheric fields that can be used to force ocean models in the AOSN-II area of interest. The atmospheric components of COAMPS include complex data quality control; a multivariate optimum interpolation (MVOI) analysis for winds and heights; model initialization; and a nonhydrostatic, multi-nested forecast model. In a related program, Air/Ocean Model and Prediction System Development, NRL has successfully used COAMPS in a similar manner for the construction of multi-year forcing fields (e.g., surface stress, precipitation, sensible and latent heat flux) for ocean models, and has demonstrated the improvement to ocean model capability through these high temporal and spatial resolution atmospheric fields.

Our second objective would be accomplished by attending AOSN-II planning meetings of the AOSN executive team and introducing new adaptive sampling strategies and new ensemble forcing strategies to AOSN.

\footnotetext{
${ }^{1}$ COAMPS is a trademark of the Naval Research Laboratory
} 


\section{Report Documentation Page}

Form Approved

OMB No. 0704-0188

Public reporting burden for the collection of information is estimated to average 1 hour per response, including the time for reviewing instructions, searching existing data sources, gathering and maintaining the data needed, and completing and reviewing the collection of information. Send comments regarding this burden estimate or any other aspect of this collection of information,

including suggestions for reducing this burden, to Washington Headquarters Services, Directorate for Information Operations and Reports, 1215 Jefferson Davis Highway, Suite 1204, Arlington

VA 22202-4302. Respondents should be aware that notwithstanding any other provision of law, no person shall be subject to a penalty for failing to comply with a collection of information if it

does not display a currently valid OMB control number.

\begin{tabular}{|c|c|}
\hline $\begin{array}{l}\text { 1. REPORT DATE } \\
\mathbf{3 0} \text { SEP } \mathbf{2 0 0 3}\end{array}$ & $\begin{array}{l}\text { 3. DATES COVERED } \\
\mathbf{0 0 - 0 0 - 2 0 0 3 ~ t o ~ 0 0 - 0 0 - 2 0 0 3 ~}\end{array}$ \\
\hline \multirow{3}{*}{$\begin{array}{l}\text { 4. TITLE AND SUBTITLE } \\
\text { Monterey Bay Sampling }\end{array}$} & 5a. CONTRACT NUMBER \\
\hline & 5b. GRANT NUMBER \\
\hline & 5c. PROGRAM ELEMENT NUMBER \\
\hline \multirow[t]{3}{*}{ 6. AUTHOR(S) } & 5d. PROJECT NUMBER \\
\hline & 5e. TASK NUMBER \\
\hline & 5f. WORK UNIT NUMBER \\
\hline $\begin{array}{l}\text { 7. PERFORMING ORGANIZATION NAME(S) AND ADDRESS(ES) } \\
\text { Naval Research Laboratory,,Monterey,,CA, 93943- }\end{array}$ & $\begin{array}{l}\text { 8. PERFORMING ORGANIZATION } \\
\text { REPORT NUMBER }\end{array}$ \\
\hline \multirow[t]{2}{*}{ 9. SPONSORING/MONITORING AGENCY NAME(S) AND ADDRESS(ES) } & 10. SPONSOR/MONITOR'S ACRONYM(S) \\
\hline & $\begin{array}{l}\text { 11. SPONSOR/MONITOR'S REPORT } \\
\text { NUMBER(S) }\end{array}$ \\
\hline
\end{tabular}

12. DISTRIBUTION/AVAILABILITY STATEMENT

Approved for public release; distribution unlimited

13. SUPPLEMENTARY NOTES

14. ABSTRACT

The goals of this project are to apply high-resolution atmosphere mesoscale modeling to ocean prediction, and assist in the design, plan, and execution of adaptive sampling strategies for the Adaptive Ocean Sampling Network II (AOSN-II) project, Monterey Bay Predictive Skill Experiment.

15. SUBJECT TERMS

16. SECURITY CLASSIFICATION OF:

a. REPORT

unclassified b. ABSTRACT

unclassified c. THIS PAGE

unclassified
17. LIMITATION OF ABSTRACT

Same as

Report (SAR)
18. NUMBER OF PAGES

6 19a. NAME OF

RESPONSIBLE PERSON 
Dr. Craig Bishop facilitated the introduction of new adaptive sampling strategies by bringing Dr. Sharanya Majumdar from the Rosensteil School of Marine \& Atmospheric Sciences (RSMAS) onto the AOSN team. Dr. Majumdar's main task was to build an Ensemble Transform Kalman Filter (ETKF) ensemble generation and targeting strategy (see Bishop et.al., 2001 and Wang and Bishop, 2003) in collaboration with Dr. Yi Chao of the Regional Ocean Modeling System (ROMS) modeling group based at the Jet Propulsion Laboratory (JPL).

\section{WORK COMPLETED}

The following work was performed during FY 03 in the two components of the project:

\section{Atmospheric forcing fields}

A four-nest grid was set up for the AOSN-II area of interest. The nests had resolutions of 81, 27, 9, and $3 \mathrm{~km}$. The $3 \mathrm{~km}$ nest was centered on the Monterey Bay and had dimensions of $199 \times 199$ grid points. The exact configuration of these grids is shown in Fig. 1. COAMPS was run every 12 hours during the AOSN-II observing period of 3 August - 8 September 2003. Each analysis utilized the previous 12 hour forecast from COAMPS for the first-guess fields. A 72 hour forecast was generated from each analysis. From these forecasts, the fields necessary to drive an ocean model were output on an hourly interval for all four grid nests. The fields provided include the $2 \mathrm{~m}$ air temperature, the surface temperature over land and water, the surface latent heat flux, the longwave radiation at surface, the $2 \mathrm{~m}$ relative humidity, the sea surface temperature, the surface sensible heat flux, the sea level pressure, the surface shortwave radiation, the $\mathrm{u}$ - and v-components of the surface stress, the total precipitation, the $\mathrm{u}$ - and v-components of the 10-m wind, and the total surface stress. These fields were placed on an ftp server for other collaborators in the AOSN II project to use.

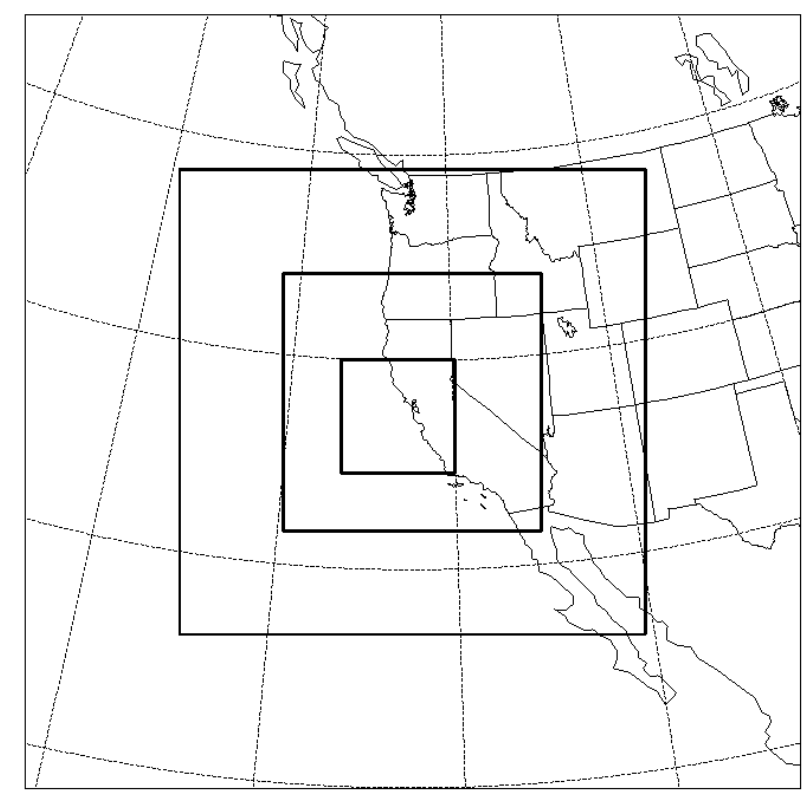

Figure 1. COAMPS grid structure for AOSN-II. Outer mesh uses $81 \mathrm{~km}$ grid spacing, first nest uses $27 \mathrm{~km}$ grid spacing, second nest uses $9 \mathrm{~km}$ grid spacing, and innermost nest uses $3 \mathrm{~km}$ grid spacing. 


\section{Adaptive sampling strategies}

In the AOSN planning meetings, presentations were given explaining how the ETKF can be used to make real time predictions of the reduction in forecast error variance due to targeted observations and to explain how the observations taken during AOSN-II could be used to test the accuracy of such predictions. Dr. Majumdar was brought into the experiment so that the ETKF computer software necessary for ensemble generation and adaptive sampling could be used by the JPL group (Dr. Chao). Soon after Dr. Majumdar began work on this project it became apparent that an ensemble of very high resolution atmospheric forcing fields would be required to force the ensemble of ocean models. However, since there were barely enough computing resources to produce a single high resolution atmospheric forecast, it was clear that some quasi-statistical ad-hoc approach would have to be used to generate an appropriate ensemble of atmospheric forcing fields. To meet this need, Dr. Bishop devised and developed a method of doing this based on smoothly deforming the high-resolution spatial forecast in space and time. Dr. Majumdar subsequently implemented this approach in the ROMS ensemble modeling system.

\section{RESULTS}

\section{Atmospheric forcing fields}

COAMPS forecasts were generated for the entire AOSN-II field program extending from 3 August through 8 September, with hourly forcing fields generated at $3 \mathrm{~km}$ resolution. Some preliminary validation of this field has begun. Significant skill has been noted in COAMPS capturing the variability of the low-level winds along the California coast. In particular, COAMPS forecast 10meter wind speeds have been compared to buoy observations in the Monterey Bay (Fig.2, next page). COAMPS short-term (0-12 hour) forecasts describe the usual diurnal variability of the winds quite well, and strong agreement is even found with the 72 hour forecast speed.

\section{Adaptive sampling strategies}

Dr. Majumdar made substantial progress in creating a real time ensemble of ocean forecasts. The new space-time deformation method for creating an ensemble of atmospheric forcing from a single high resolution atmospheric run was shown to provide a highly controllable method of perturbing high resolution surface winds. While some tuning is still required, the results so far have been very encouraging. Largely because of a lack of computing resources at JPL (where ROMS was being run) it was generally not possible to make oceanic ensemble forecasts during the field phase of AOSN. However, a new computer is on its way to JPL that should ameliorate this difficulty. 

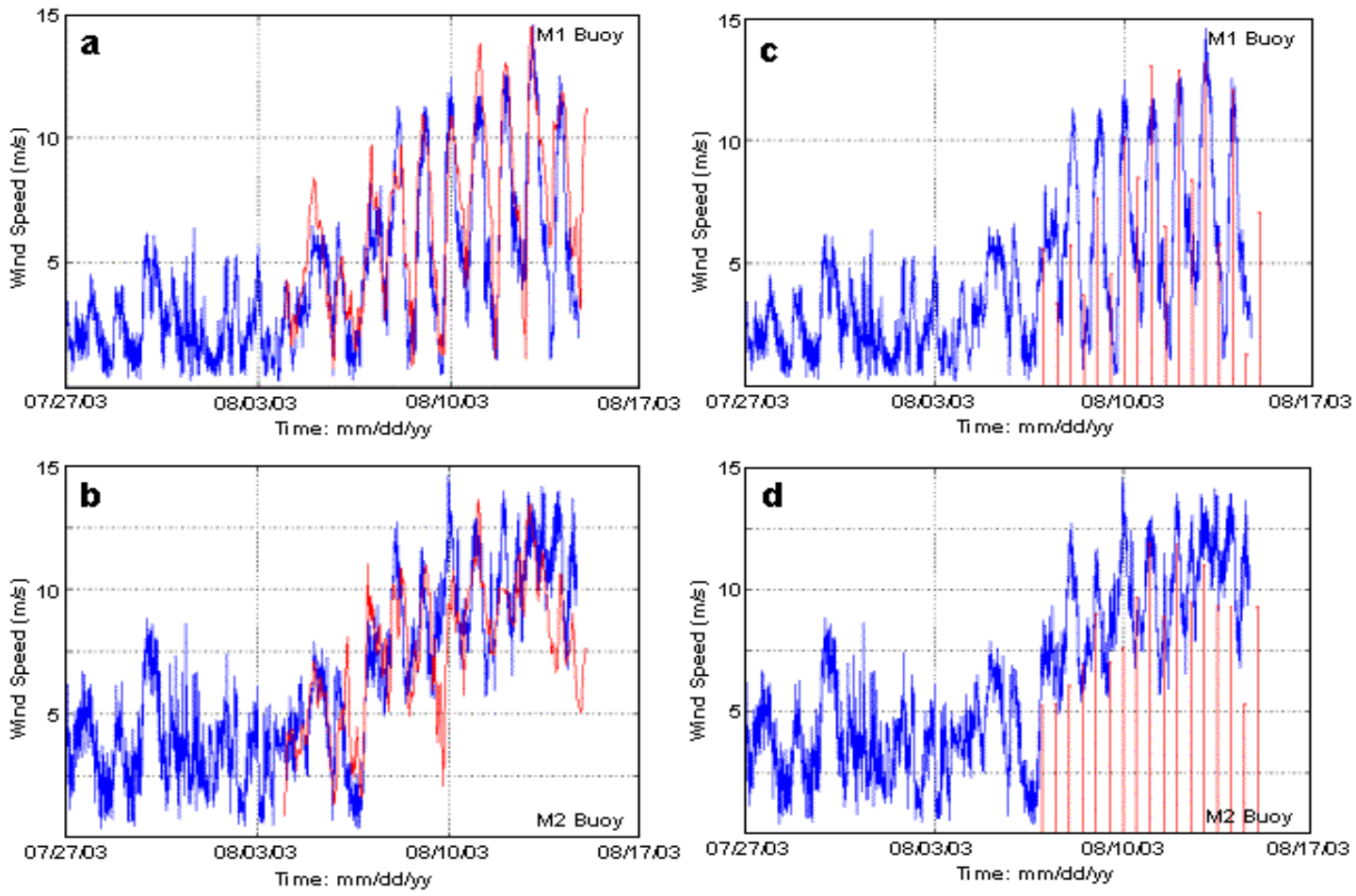

Figure 2. COAMPS wind forecasts (red) and verifying buoy observations (blue) of 10-meter wind speed for 27 July - 17 August 2003 for buoys M1 and M2 in the Monterey Bay. (a) represents COAMPS 0-12 hour wind forecasts at M1, (b) represents COAMPS 0-12 hour wind forecasts at M2, (c) represents COAMPS 72 hour wind forecasts at M1, and (d) represents COAMPS 72 hour wind forecasts at $M 2$.

\section{IMPACT/APPLICATIONS}

The high-resolution COAMPS atmospheric forecasts created for AOSN-II should have a profound impact on ocean prediction. Preliminary studies indicate the need for such high-resolution fields to properly simulate the scale and position of coastal jets. Coarser resolution fields cannot resolve these scales and, therefore, the curl of wind stress is wrong, leading to inaccurate ocean prediction.

The development of an ETKF ensemble generation and targeting techniques for oceanic models will enable probabilistic forecasting and a highly flexible solution to the problem of adaptive observational network design. Previously, the ETKF had only been used in atmospheric ensemble generation and adaptive sampling problems (Majumdar et al. 2001, 2002, Szunyogh et al., 2000, Wang and Bishop, 2003). Thus, AOSN is enabling these techniques to be transitioned from atmospheric to oceanic applications.

\section{TRANSITIONS}

The fully coupled COAMPS will eventually transition to 6.4 projects within PE $0603207 \mathrm{~N}$ (SPAWAR, PMW-185) that focus on the transition of COAMPS and COAMPS-On Scene (COAMPS-OS ${ }^{\text {TM}) ~ t o ~}$ FNMOC, and the transition of the ocean data assimilation system for COAMPS. In collaboration with Dr. Xiaodong Hong of NRL, the space-time deformation ensemble generation technique for high- 
resolution surface winds/forcing together with the ETKF will be incorporated into NRL's suite of forecasting tools in fall 2004.

\section{RELATED PROJECTS}

The COAMPS fields generated as part of this project will be used in related 6.1 projects within PE $0601153 \mathrm{~N}$ that include studies of fetch-limited and orographic flows and atmospheric physics, in related 6.2 projects within PE $0602435 \mathrm{~N}$ that focus on the development of the atmospheric components (QC, analysis, initialization, and forecast model) of COAMPS, and in our ONR 6.2 Air/Ocean Model and Prediction System Development project.

\section{REFERENCES}

Bishop, C.H., B.J., Etherton and S.J. Majumdar, 2001: Adaptive Sampling with the Ensemble Transform Kalman Filter. Part I: Theoretical Aspects. Mon. Wea. Rev. 129, 420-436.

Hodur, R. M., 1997: The Naval Research Laboratory’s Coupled Ocean/Atmosphere Mesoscale Prediction System (COAMPS). Mon. Wea. Rev., 125, 1414-1430.

Teague, W. J., M. J. Carron, and P. J. Hogan, 1990. A comparison between the Generalized Digital Environmental Model and Levitus climatologies. J. Geophys. Res., 95 (C5), 7167-7183.

Majumdar, S.J., C.H. Bishop, I. Szunyogh and Z. Toth, 2001: Can an Ensemble Transform Kalman Filter predict the reduction in forecast error variance produced by targeted observations?. Quart. J. Roy. Met. Soc. 127, 2803-2820.

Majumdar, S.J., C.H.Bishop, B.J.Etherton and Z.Toth, 2002: Adaptive Sampling with the Ensemble Transform Kalman Filter. Part II: Field Program Implementation. Mon. Wea. Rev., 130, 1356-1369.

Szunyogh, I., Toth, Z., Morss, R.E., Majumdar, S. Etherton, B.J. and C.H. Bishop, 2000: The effect of targeted dropsonde observations during the 1999 Winter Storm Reconnaissance Program. Mon. Wea. Rev. 128, 3520-3537.

Wang, X. and C.H. Bishop, 2003: A comparison of Breeding and Ensemble Transform Kalman Filter Forecast Schemes. J. Atmos. Sci., 60, 1140-1158. 